\title{
Overcorrection in Mandibular Advancement ${ }^{\star}$
}

\author{
Peter Egyed \\ Department of Maxillo-Facial Surgery (Head: Prof. P. Egyedi, M.D., D.M.D.), University of \\ Utrecht, Holland
}

\begin{abstract}
Summary
Seven cases of class II skeletal deformities of the face are described in which overcorrection into a class III relationship was performed. This concept is based on the unpredictability of the relapse tendency on the one hand and the anterior inclination of the lower front teeth in some cases (which may block mandibular advancement significantly) on the other hand.

Depending on the degree of the relapse occurring, postoperative orthodontic treatment, a second segmental operation or mere occlusal grinding is required.
\end{abstract}

Key-Words: Mandibular advancement; Mandibular retrognathia; Overcorrection; Ankylosis

\section{Introduction}

The relapse problem in surgical correction of mandibular retrusion is fraught with a number of complications of which occlusal relapse is seen rather frequently. Proper mobilization of the anterior part of the mandible during the osteotomy is mandatory and a good interdigitation postoperatively is of some help in preventing the mandible from sliding backwards.

Muscular traction, however, often causes a partial relapse. Also interdigitation is not always such that a reliable guidance of the mandible during mastication is ensured.

A second problem in mandibular advancement is the shape of the dental arches and the inclination of the front teeth. Sometimes a good occlusion is cephalometrically not satisfactory as far as the position of the chin is concerned. Therefore for several years, in selected cases we have placed the

\footnotetext{
"Dedicated to Prof. Dr. H. L. Obwegeser on the occasion of his $60^{\text {th }}$ anniversary
}

mandible in a cephalometrically proper position disregarding the occlusion and in fact obtained a reversed incisal relationship ("class III") in some cases.

In this article our experience will be discussed.

\section{Materials and Methods}

\section{The patients}

There were seven patients. Two were operated on for unilateral ankylosis which had resulted in a severe class II position of the mandible, with anterior tilting of the lower incisors.

Three cases were operated on for oto-mandibular dysostosis. There were two cases with a "normal" underdevelopment of the mandible.

\section{Surgical techniques}

The two ankylosis cases were operated on by simultaneousely freeing the ankylosis and performing a sagittal split-type osteotomy of the mandible (Obwegeser 1955, 1957; Dal Pont 1959) on the healthy side and a costochondral rib-graft (Bromberg et al. 1963) on the affected side.

The operation was commenced by submandibular exposure of the joint area in the usual way, removing excess bone in the fossa articularis and thus freeing the condylar process, removing the muscular process and interposing the graft into the gap after doing the sagittal split on the other side. Intermaxillary fixation was maintained for six weeks and $1 \frac{1}{2}$ years after the first operation in one case a Hullihen-procedure was done to bring the anterior lower alveolus into a correct position.

The oto-mandibular dysostosis cases were treated by a costochondral graft only, with rotation of the mandible towards the unaffected side. In one case 


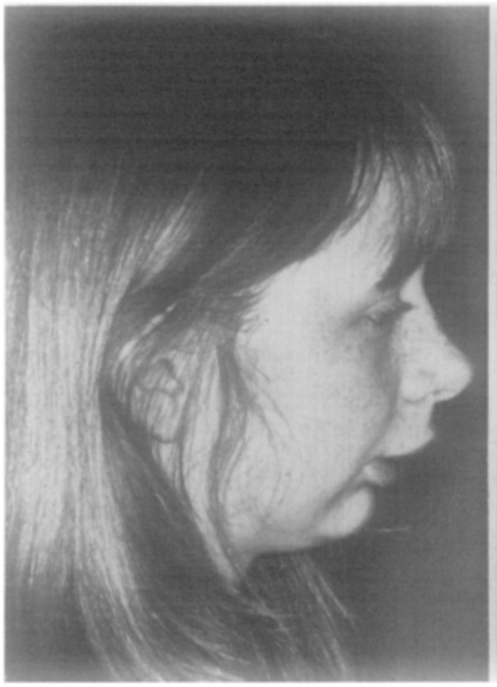

Fig. $1 \mathrm{a}$

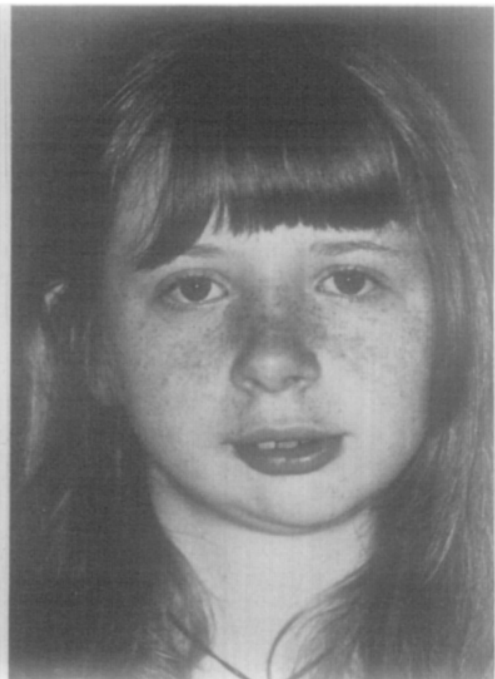

Fig. $1 \mathrm{~b}$

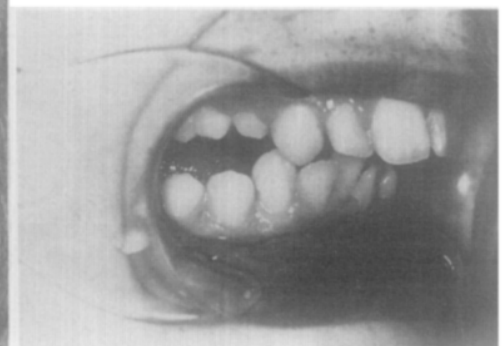

Fig. $1 \mathrm{C}$

Fig. 1 Case of ankylosis.

Fig. $1 \mathrm{a}, \mathrm{b}$ Pre-operative view of the face.

Fig. 1c Pre-operative occlusion.

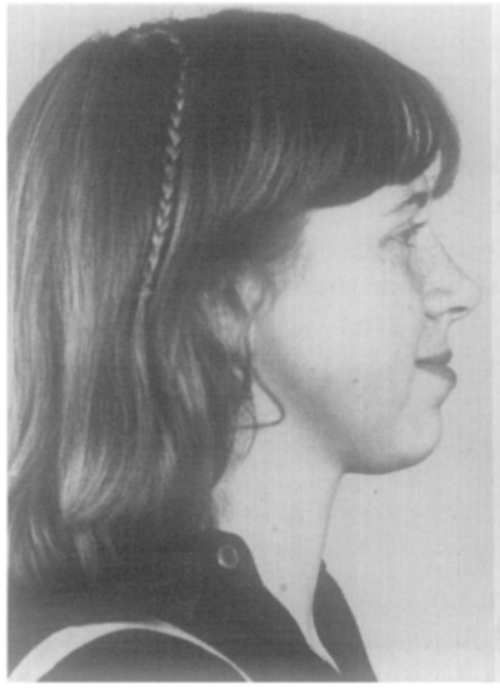

Fig. 1d

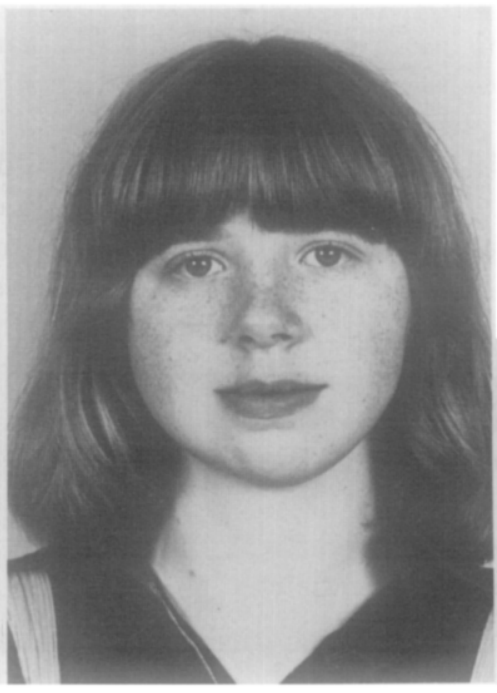

Fig. 1e

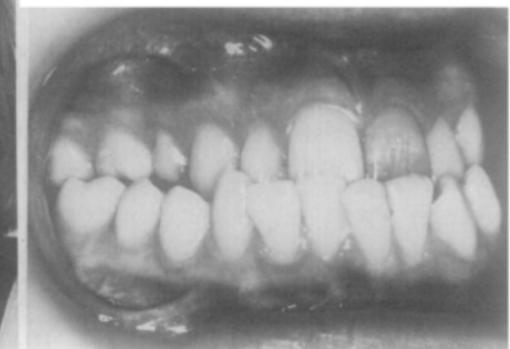

Fig. $1 f$

Fig. 1d, e Appearance after advancement of the mandible. The lower lip is protruding.

Fig. $1 \mathrm{f}$ Occlusion after the advancement of the mandible. There is a reverse incisal relationship; good interlocking.

it was decided to reconstruct the articular fossa (Obwegeser 1974) in order to obtain a more stable abutment for the graft.

The two "normal" cases were treated by the sagittal splitting procedure.

\section{Results}

A. The ankylosis cases

Mouth opening was normal in both cases after more than three years. They had been operated upon at the age of 18 and 15 . 


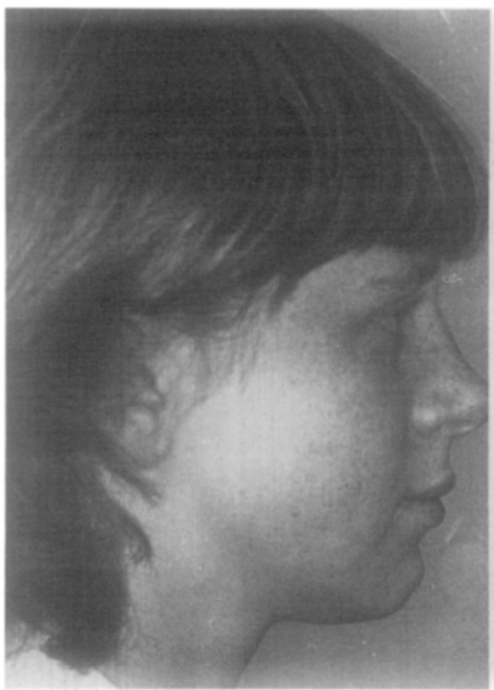

Fig. $1 \mathrm{~g}$

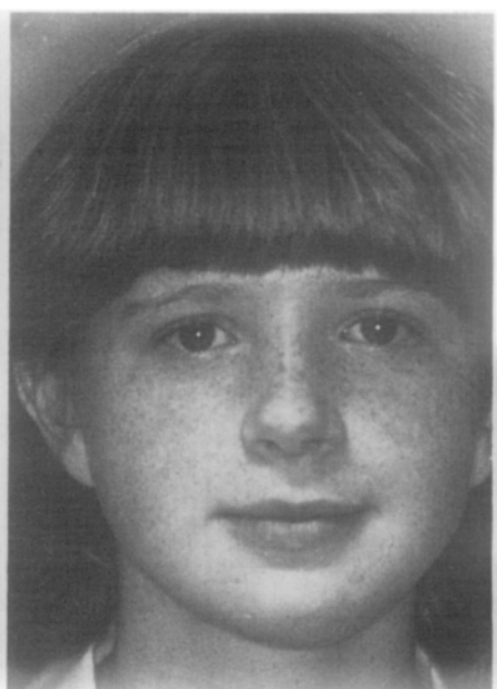

Fig. $1 \mathrm{~h}$

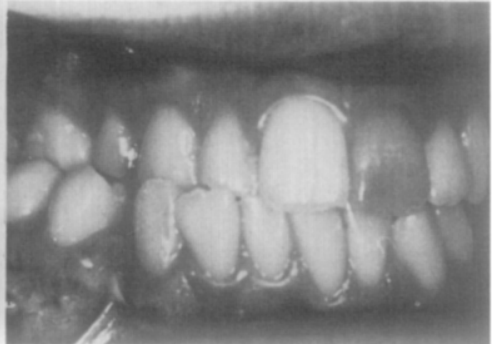

Fig. 11

Fig. $1 \mathrm{~g}, \mathrm{~h}$ Appearance 2 years after the Hullihen-osteotomy.

Fig. $1 \mathrm{i}$ Occlusion 2 years after the Hullihen-osteotomy.

The first case sustained a slight occlusal relapse; after grinding the teeth the occlusion was satisfactory. There was an edge-to-edge position of the incisors and the chin was more or less in its proper place.

The second patient is depicted (Fig. 1), the result was excellent as can be seen.

\section{B. Dysostosis oto-mandibularis}

Two of the three cases, operated on at the age of 17 and 18 respectively, were failures. The grafts eventually resorbed and a complete relapse in the occlusion occurred. The temporary surgical correction may, however, have promoted development of the maxilla during the years the mandible was positioned further anteriorly and caudally.

The third case, 6 years old, in which a fossa articularis was constructed is still too young for a final assessment but at this moment the result seems better. The operation, however, was done only one year ago and therefore no definite conclusion can be drawn as yet.

\section{The "normal" class II cases}

One of the two cases, aged 18 , sustained a partial relapse and the result was an edge-to-edge incisal relationship and a satisfactory appearance.

The other case, 23 years old, is depicted in figure 2, the patient is still considering whether or not she wants a normal incisal relationship restored.

If she were to decide to have this done, a "reverse Wunderer-procedure" would be required and the only problem in this procedure is the palatal incision which must ensure that there is covering of the osteotomy line after advancement of the anterior fragment (Fig. 3).

\section{Discussion}

Presurgical orthodontic treatment in severe disproportions is in general rejected by this author because a partial postsurgical relapse may require renewed orthodontics. It seems only justified if a single tooth (maybe two teeth) prevents the mandible or maxilla from being brought into the cephalometrically required position.

The better policy in severe disproportions seems to be to put the jaw fragments in their cephalometrically correct position and adjust the arches orthodontically/prosthetically after bony consolidation is complete.

In skeletal class II cases a very useful procedure to achieve an acceptable appearance is genioplasty. We always use the method described by Obwe- 


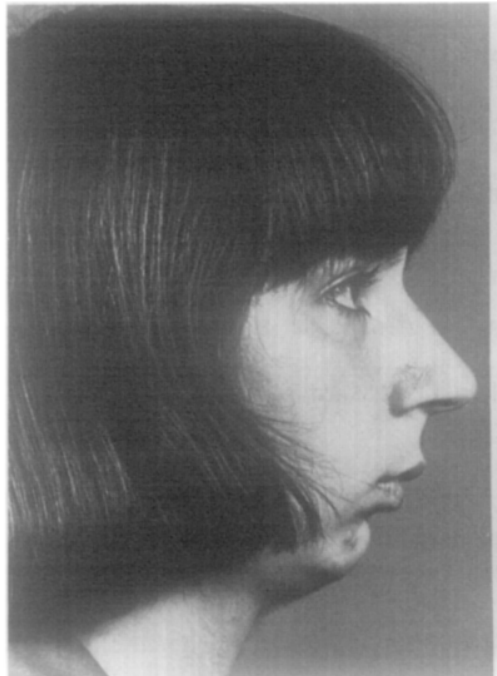

Fig. $2 \mathrm{a}$

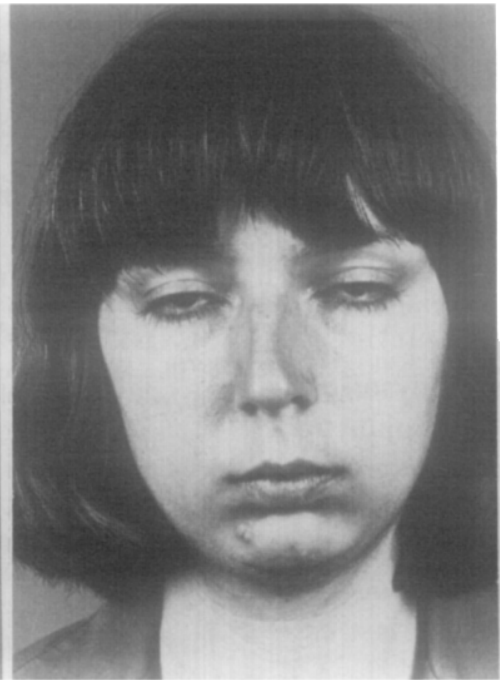

Fig. $2 b$

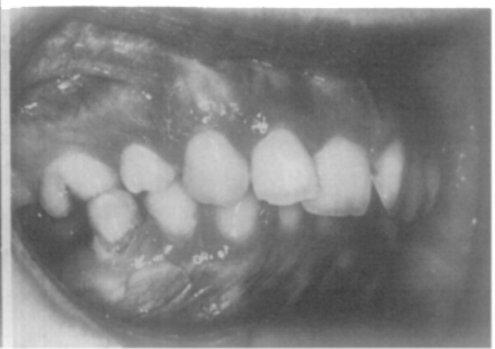

Fig. 2c

Fig. 2 Case of "normal" class II relation.

Fig. 2a, b Pre-operative views of the face.

Fig. 2c Pre-operative occlusion.

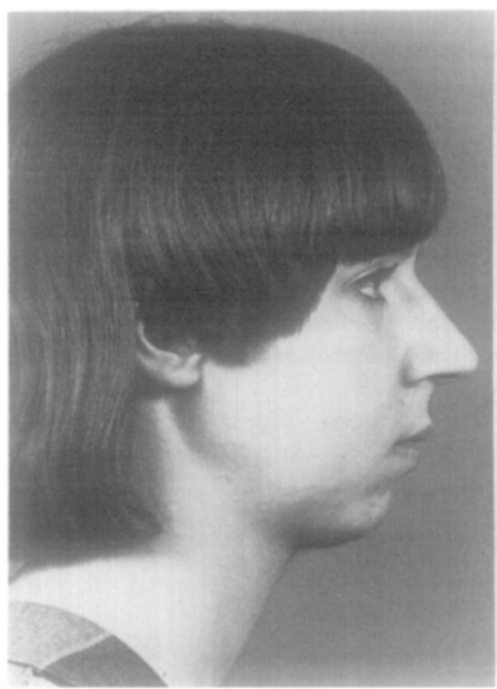

Fig. $2 d$

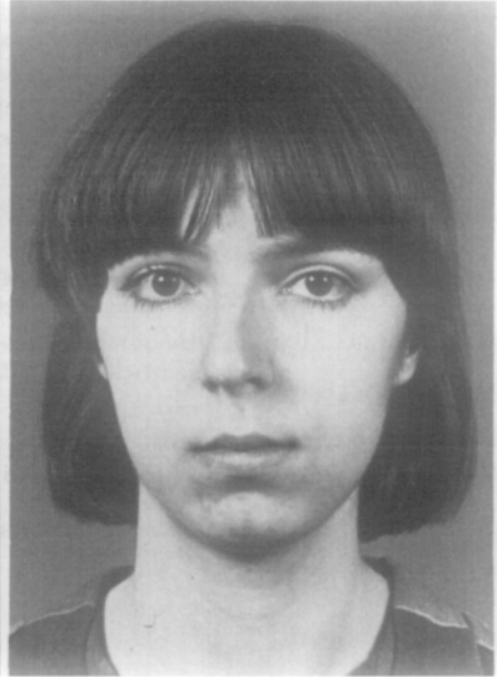

Fig. $2 e$

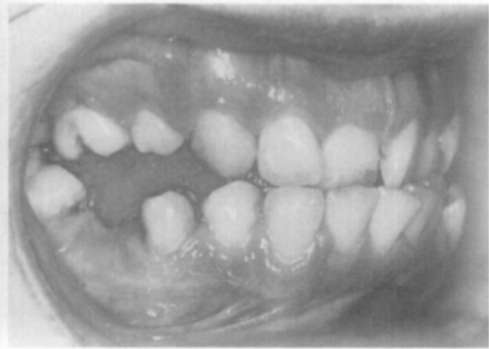

Fig. $2 f$

Fig. $2 d$, e Appearance after advancement of the mandible. Chin position seems correct. Fig. $2 f$ Occlusion after advancement of the mandible, good interlocking in incisor region. Post-operative orthodontics and/or crown- and bridgework required.

geser (1957) but an ideal contour of the chin area is not always obtained (Wegener 1971).

Considering all this, our approach nowadays is: a. bring the mandible into a cephalometrically acceptable position; a slight overcorrection is desirable,

b. don't hesitate to produce a reverse incisal relationship especially if this provides good interlocking, 
c. do an alveolar osteotomy or/and orthodontics/ prosthetics after complete consolidation of the fragments.

It should be stressed, that this idea of over-correction in orthognathic surgery is not new. Hovell introduced this concept for mandibular protrusion in 1960 and the thoughts advocated in this article should be seen as an adaptation to the skeletal class II situation.

As to the three cases of oto-mandibular dysostosis, the operations were performed in conjunction with Converse's et al. (1973) concept of promoting (maxillary) development, although we were well aware of Hovell's (1961) pessimistic opinion on bone grafts in these cases. The final occlusal results were unfavourable except in the last case (where follow-up is too short, however).

Maybe one should exclude the branchial arch syndromes for the time being from the above mentioned concepts, as long as the favourable effect on growth of the facial structures has not been firmly established.

\section{Conclusion}

Except in branchial arch defects the results in advancement of the mandible with overcorrection seem satisfactory. Until methods are devised for prediction of the amount of relapse which can be expected after osteotomies there is only a limited scope for pre-operative orthodontics in severe disproportions of the skeletal class II type.

\section{References}

Bromberg, B. E., R. H. Walden, L. R. Rubin: Mandibular bone grafts - a technique in fixation. Plast. Rec. Surg. 32 (1963) 589

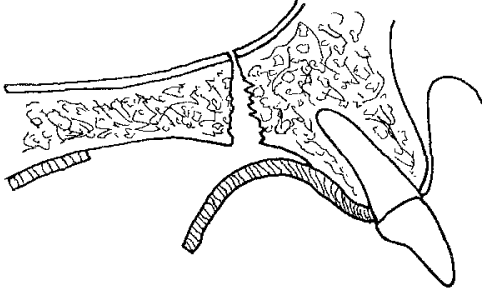

Fig. 3 Palatal flap required for the "reverse Wunderer" operation. The gap should be covered by the flap, an area of palatal bone is left for secondary healing.

Converse, J. M., S. L. Horowitz, P. J. Coccardo, D. WoodSmith: The corrective treatment of the skeletal asymmetry in hemifacial microsomia. Plast. Rec. Surg. 52 (1973) 221

Hovell, J. H.: Surgical treatment of mandibular prognathism. Ann. Roy. Coll. Surg. Engl. 27 (1960) 388

Hovell, J. H.: Discussion remark. Trans. Eur. Orth. Soc., Albani, The Hague 1961

Obwegeser, H.: In: The surgical correction of mandibular prognathism and retrognathia with consideration of genioplasty. Oral surg. Oral med. Oral Path. 10 (1957) 787

Obwegeser, H.: Correction of the skeletal anomalies of otomandibular dysostosis. J. Max. Fac. Surg. 2 (1974) 73

Obwegeser, $H$ : In: Trauner, R. und $\mathrm{H}$, Obwegeser: Zur Operationstechnik bei der Progenie und anderen Unterkieferanomalien. Dtsch. Zahn-, Mund- und Kieferheilk. 23 (1955) 1

Dal Pont, G.: L'osteotomia retromolare per la correzione della progenia. Min. Clin. 18 (1959) 1138

Wegener, A.: Eine klinische und röntgenzephalometrische Nachuntersuchung der Ergebnisse der chirurgischen Kinnvorverschiebeplastik nach Obwegeser. Med. Diss. Zürich, Juris 1971

Prof. P. Egyedi, M.D., D.M.D.

Afd. Kaakchirurgie

Academisch Ziekenhuis

Catharijnesingel 101

3511 GV Utrecht

The Netherlands 